\title{
Health Care Provider Identifier
}

National Cancer Institute

\section{Source}

National Cancer Institute. Health Care Provider Identifier. NCI Thesaurus. Code C93843.

A unique symbol that establishes identity of the healthcare provider. 